\title{
Correction to: Costs of inpatient hospitalisations in the last year of life in older New Zealanders: a cohort study
}

Oliver W. Scott ${ }^{1 *}$, Merryn Gott ${ }^{2}$, Richard Edlin ${ }^{1}$, Simon A. Moyes ${ }^{1}$, Marama Muru-Lanning $^{3}$ and Ngaire Kerse $^{1}$

Correction to BMC Geriatr 21, 514 (2021).

https://doi.org/10.1186/s12877-021-02458-6

Several errors were introduced during publication of the original article [1]. These errors are as follows:

1. Additional file 1 (Calculation of the costs of hospital-level care in residential settings in New Zealand) and the in-text citation of this file were missing.

2. Additional file 1 (Supplementary Tables and Figures) should be Additional file 2 .

3. The footnote clarifying NZDep groups was missing in Table 1 and Additional file 2:

a. NZDep was categorised as the following: $1-4$, $5-7$, and $8-10$, where 1 represents the areas with the least deprived scores and 10 the areas with the most deprived scores.

These changes do not impact the conclusion of the article. The original article has been updated to rectify these errors. The publisher apologizes to the authors and readers for the inconvenience.

\begin{abstract}
Author details
${ }^{1}$ School of Population Health, University of Auckland, 85 Park Road, Grafton, Auckland 1023, New Zealand. ${ }^{2}$ School of Nursing, University of Auckland, 85 Park Road, Grafton, Auckland 1023, New Zealand. ${ }^{3}$ James Henare Research Centre, University of Auckland, 18 Wynyard Street, Auckland Central, Auckland 1010, New Zealand.
\end{abstract}

Published online: 15 December 2021

\section{Reference}

1. Scott OW, Gott M, Edlin R, et al. Costs of inpatient hospitalisations in the last year of life in older New Zealanders: a cohort study. BMC Geriatr. 2021;21:514. https://doi.org/10.1186/s12877-021-02458-6. regulation or exceeds the permitted use, you will need to obtain permission directly from the copyright holder. To view a copy of this licence, visit http://creativecommons.org/licenses/by/4.0/. The Creative Commons Public Domain Dedication waiver (http://creativeco mmons.org/publicdomain/zero/1.0/) applies to the data made available in this article, unless otherwise stated in a credit line to the data. 